\title{
THE USE OF MAGNESIUM SULPHATE AS A LOCAL APPLICATION IN INFLAMMATION OF THE CONJUNCTIVA AND CORNEA \\ BY
}

H. KIRKPATRICK,

MAJOR I.M.S.; SUPERINTENDENT, GOVERNMENT OPHTHALMIC HOSPITAL, MADRAS. SINCE the time when the value of induction of osmosis and lymph flow by the use of hypertonic solutions was recognized in the treatment of war wounds, magnesium sulphate solutions have been in constant use at the Madras Government Ophthalmic Hospital in the treatment of inflammatory conditions of the conjunctiva and surface of the cornea, and over four years' experience have fully convinced me of its great value as a remedy in such diseases.

In the majority of suppurative ulcerations of the cornea the pain is relieved and the surface cleaned in a striking manner, though it must be confessed that it does not act with an equal degree of success in all cases, possibly owing to a lower antitoxic and bactericidal lymph value in such patients. It can be claimed, however, that in most cases the ulcer heals with less pain and less scarring as a result of its use. It is the custom to administer 15 grains of urotropin every three hours with, of course, atropin locally, and under such treatment it is only rarely found necessary to cauterize the ulcer or perform a paracentesis. A bandage is not generally used.

Eyes suffering from trachoma with a secondary infection are not uncommonly met with, and these generally respond to the magnesium sulphate treatment in a very gratifying way. It is, however, in gonorrhoeal ophthalmia, with its associated chemotic condition, that the treatment has its most marked success, and, as far as I am aware, no eye which was in a reasonable condition when first seen has been lost from this disease since our present routine treatment was adopted.

The action of magnesium sulphate in all chemotic conditions has been found most satisfactory, and even in suppurative panophthalmitis it will often reduce the swelling of the tissues, free the patient from pain, and sometimes allow him to keep his eyeball-a very important matter in a country where an artificial eye is unlikely to be worn or be properly cared for if obtained.

The strength of the solution used varies from 40 grains to the ounce to saturation, and this is applied in an eye bath for five minutes every two or three hours; in addition, the conjunctival sac is thoroughly irrigated by the surgeon once a day or oftener. In cases of gonorrhoeal ophthalmia both urotropin and stock gonococcal vaccines are given as well.

It is possible that hypertonic solutions are already extensively used in the manner described, but I have seen no reference to them in any literature to which I have access. 